\title{
Comparison of total laparoscopic hysterectomy and laparoscopic assisted vaginal hysterectomy - a 2-year retrospective study
}

\section{Kanmani Mani*, Mirudhubashini Govindarajan, Vishranthi Selvaraj}

\author{
Department of Obstetrics and Gynecology, Women’s Center Hospitals, Coimbatore, Tamilnadu, India
}

Received: 23 December 2016

Accepted: 31 January 2017

\author{
*Correspondence: \\ Dr. Kanmani Mani, \\ E-mail: drmkdpi@gmail.com
}

Copyright: (C) the author(s), publisher and licensee Medip Academy. This is an open-access article distributed under the terms of the Creative Commons Attribution Non-Commercial License, which permits unrestricted non-commercial use, distribution, and reproduction in any medium, provided the original work is properly cited.

\begin{abstract}
Background: Hysterectomy is one of the most commonly performed major surgeries. Recently, increasing number of minimally invasive approaches, such as TLH and LAVH has been applied. People undergoing laparoscopic hysterectomy experience shorter hospitalization, a smaller wound, more rapid recovery, and shorter absence from work compared to patients undergoing abdominal hysterectomy. The objective of present study is to compare the surgical short term results between Laparoscopic assisted vaginal hysterectomy (LAVH) and Total laparoscopic hysterectomy (TLH) in our centre in two years.

Methods: This was a retrospective study of 93 women who underwent LAVH and 55 women who underwent TLH. The statistical analysis is done by using Students t-test, Chi-square test, and Mann-Whitney test appropriately.

Results: There were no differences between the two groups with respect to age, BMI, Indication of surgery, Uterine size, Previous pelvic surgery, average blood loss and hemoglobin change $(\mathrm{P}=0.4)$. The duration of surgery was longer in TLH (124 min vs. $76.9 \mathrm{~min})$ and is found to be extremely significant $(\mathrm{P}=0.0001)$. There was significant statistical difference in respect to hospital stay $(\mathrm{P}=0.0076)$. There was no significant statistical difference in various complication rates $(\mathrm{P}=0.22)$.

Conclusions: Both TLH and LAVH are safe methods in performing hysterectomy, but LAVH has advantages over TLH with reduced operating time and less hospital stay even for the patients with history of previous pelvic surgery.
\end{abstract}

Keywords: Complications, Laparoscopic assisted vaginal hysterectomy, Total laparoscopic hysterectomy

\section{INTRODUCTION}

Hysterectomy is one of the most commonly performed major surgeries. Recently, increasing number of minimally invasive approaches, such as TLH and LAVH has been applied. People undergoing laparoscopic hysterectomy experience shorter hospitalization, a smaller wound, more rapid recovery, and shorter absence from work compared to patients undergoing abdominal hysterectomy. The disadvantages are longer operating time, higher costs and experience required for laparoscopy including a learning curve. ${ }^{1-5}$ Most of the surgeons do not feel comfortable enough with the vaginal approach, especially in the presence of dense adhesions, the need for oophorectomy, narrow vaginal access, and lack of pelvic relaxation. ${ }^{3-5}$ In our facility, LAVH had also been performed for benign lesions routinely. However, with the growing prevalence of laparoscopic surgery, we have started doing TLH to substitute LAVH. The aim of our study was to examine whether introduction of TLH in a centre where LAVH has been performed predominantly has any risks in respect to complication rates and hospital stay.

\section{METHODS}

A Retrospective non randomised study was carried out in Womens center hospital, Tamilnadu, India comparing 
TLH and LAVH. The study period was from June 2014 to May 2016 (24 months). Medical records and theatre register of the patients were identified and reviewed; factors examined include demographic details, indication for operation, intra-operative details, histopathology summary, post-operative recovery and subsequent postoperative review findings. Number of patients included in this study was 148 , of which 55 patients underwent TAH and 93 underwent LAVH. Patients with malignancies and planned vaginal or abdominal hysterectomies were excluded.

In present study, the distribution of patient characteristics and indications of hysterectomy is listed in Table 1. Intra and post-operative results were listed in Table 2. All patients had pathologically confirmed benign lesions.

\section{Operative techniques}

LAVH - LH was performed as follows. After creating pneumoperitoneum with carbondioxide, exploration of the upper abdomen and pelvic adhesiolysis were done, if necessary. When the ovaries were to be conserved, the Fallopian tubes, round and utero-ovarian ligament were resected with bipolar forceps and harmonic. For adnexectomy, mesosalpinx, round and infundibulopelvic ligament were resected. After laparoscopic dissection of the bladder flap and resection of the broad ligaments, vaginal route of procedure started by making anterior and posterior colpotomies, then clamping, transecting, and suture ligating of uterine vessels, cardinal and uterosacral ligaments and finally closure of peritoneum and vaginal vault anchored to the cardinal-uterosacral ligament complex after removing uterus. Because the uterine vessels were secured vaginally, this procedure is classified as LAVH.

$T L H$ - The procedure was performed same as LAVH above the uterine artery level. After laparoscopic dissection of the bladder flap and resection of the broad ligament, the uterine artery was coagulated by bipolar coagulation and was separated from the uterine sidewall by harmonic. Then bilateral coagulation and transection of the cardinal-uterosacral ligament complex were performed carefully. The cervicovaginal junction was confirmed with vaginal tube through the vagina. Circular colpotomy was then performed close to the cervix. The uterus was removed through the vagina and sent for histological examination. Endosutures were placed on the vaginal cuff. The duration of operation was calculated from the first skin incision for the Veress needle insertion to the last suture of the abdominal wound. Blood loss was calculated from aspiration and pad soakage. Postoperative medication was administered intravenously for analgesia and cefazolin intravenously, for prophylaxis for the first $24 \mathrm{hr}$.

Febrile morbidity was defined as an oral temperature of $100.4^{\circ} \mathrm{F} / 38.0^{\circ} \mathrm{C}$ or higher, excluding the first $24 \mathrm{~h}$ postoperatively. Duration of hospital stay was calculated from the day of surgery to the day of discharge. Patients were discharged when they were afebrile, with normal voiding, and off analgesic. A statistical analysis of the data was performed using unpaired Student's t test, Mann-Whitney U, Fisher exact test for parametric or nonparametric variables and the chi-square test, where appropriate, for categorical variables. Linear correlation was done to find significance between operative time and blood loss. $\quad \mathrm{P}<0.05$ was considered statistically significant.

\section{RESULTS}

This retrospective study assigned 93 women in LAVH group and 55 women in TLH group. There was no statistically significant difference between two groups with mean age, BMI, the prevalence of previous pelvic surgery and the indication of hysterectomy (Table 1). Mean parity is significant in between two groups $(\mathrm{P}=0.001)$. This signifies selection of patients for LAVH will have some descent of uterus of better accessibility. Significant number of patients with scarred uterus were selected for TLH $(\mathrm{P}=0.002)$. Indications for mode of surgery between two groups were not significant except in DUB, as the uterus without any anatomical abnormality and freely mobile uterus were chosen LAVH.

Table 1: Distribution of patient characteristics and Indication of surgery.

\begin{tabular}{|c|c|c|c|}
\hline & $\begin{array}{l}\text { LAVH } \\
(\mathrm{n}=93)\end{array}$ & $\begin{array}{l}\text { TLH } \\
(n=55)\end{array}$ & P value \\
\hline Age (years) & $47 \pm 7.2$ & $46.9 \pm 6.9$ & $0.93^{\mathrm{a}}$ \\
\hline BMI & $27.7 \pm 5.5$ & $26 \pm 4.7$ & $0.56^{\mathrm{a}}$ \\
\hline Parity & $1.95 \pm 0.7$ & $1.56 \pm 0.7$ & $0.001^{\mathrm{a}}$ \\
\hline Caesarean delivery & $0.2 \pm 0.6$ & $0.55 \pm 0.8$ & $0.002^{\mathrm{a}}$ \\
\hline \multicolumn{4}{|c|}{ Previous pelvic surgery } \\
\hline Sterilisation & 32 & 12 & \\
\hline Myomectomy & 0 & 2 & \\
\hline Adnexectomy & 1 & 0 & \\
\hline Total & $33(33.5)$ & $14(25.4)$ & $0.2^{\mathrm{b}}$ \\
\hline \multicolumn{4}{|l|}{ Indication of surgery } \\
\hline Fibroid & $52(56)$ & $37(67)$ & $\mathrm{NS}^{\mathrm{b}}$ \\
\hline Adenomyosis & $22(23)$ & $12(21)$ & $\mathrm{NS}^{\mathrm{b}}$ \\
\hline Endometriosis & $2(0.2)$ & $3(5.5)$ & $\mathrm{NS}^{\mathrm{b}}$ \\
\hline Ovarian cyst & $7(0.8)$ & $1(1.8)$ & $\mathrm{NS}^{\mathrm{b}}$ \\
\hline DUB & $19(20)$ & $2(3.7)$ & $0.01^{\mathrm{b}}$ \\
\hline
\end{tabular}

LAVH-Laparoscopic assisted vaginal hysterectomy, TLHTotal laparoscopic hysterectomy; Values are given as mean \pm SD or n (\%); a-Student's t test, b-Chi-square test.

As shown in Table 2, TLH required longer duration $(124 \pm 39.7 \mathrm{~min}, \mathrm{P}=0.0001)$ than LAVH $(76.9 \pm 25)$ Table 2. The mean blood loss in TLH is higher than LAVH, but there was no statistically significant difference $(\mathrm{P}=0.1)$. The mean duration of hospital stay is less in LAVH than TLH and was statistically significant $(\mathrm{P}=0.008)$. There was no significant difference in uterine size $(\mathrm{P}=0.49)$ and hemoglobin change $(\mathrm{P}=0.46)$. 
Table 2: Intra and post-operative results.

\begin{tabular}{|c|c|c|c|}
\hline & $\begin{array}{l}\text { LAVH } \\
(n=93)\end{array}$ & $\begin{array}{l}\text { TLH } \\
(n=55)\end{array}$ & $P$ value \\
\hline $\begin{array}{l}\text { Duration of } \\
\text { surgery, min }\end{array}$ & $76.9 \pm 25$ & $124 \pm 39.7$ & $0.0001^{\mathrm{a}}$ \\
\hline Blood losses, ml & $123.3 \pm 132$ & $163 \pm 149$ & $0.1^{\mathrm{b}}$ \\
\hline $\begin{array}{l}\text { Hospital stay, } \\
\text { days }\end{array}$ & $4.21 \pm 0.69$ & $4.63 \pm 1.2$ & $0.008^{a}$ \\
\hline Uterine size, $\mathrm{cm}$ & $11.45 \pm 8.2$ & $11.16 \pm 2.9$ & $0.49^{\mathrm{b}}$ \\
\hline \multicolumn{4}{|l|}{ Complications } \\
\hline $\begin{array}{l}\text { Hemoglobin } \\
\text { change, g\% }\end{array}$ & $1.03 \pm 0.73$ & $1.12 \pm 0.7$ & $0.46^{\mathrm{a}}$ \\
\hline Vault hematoma & $4(4.3)$ & $1(1.8)$ & $\mathrm{NS}^{\mathrm{c}}$ \\
\hline Fever & $4(4.3)$ & $2(3.6)$ & $\mathrm{NS}^{\mathrm{c}}$ \\
\hline Bowel injury & 0 & $1(1.8)$ & $\mathrm{NS}^{\mathrm{c}}$ \\
\hline Bladder injury & 0 & $1(1.8)$ & $\mathrm{NS}^{\mathrm{c}}$ \\
\hline Ureteric injury & 0 & $1(1.8)$ & $\mathrm{NS}^{\mathrm{c}}$ \\
\hline $\begin{array}{l}\text { Wound } \\
\text { infection }\end{array}$ & $1(1.1)$ & 0 & $\mathrm{NS}^{\mathrm{c}}$ \\
\hline Conversion & $1(1.1)$ & $1(1.8)$ & $\mathrm{NS}^{\mathrm{c}}$ \\
\hline Repeat surgery & $2(2.1)$ & $3(5.5)$ & $\mathrm{NS}^{\mathrm{c}}$ \\
\hline
\end{tabular}

LAVH-Laparoscopic assisted vaginal hysterectomy, TLHTotal laparoscopic hysterectomy; Values are given as mean $\pm \mathrm{SD}$ or $\mathrm{n}[\%]$. NS = Not significant; a-Student's t test; $\mathrm{b}-$ Mann-Whitney U test; c Fisher's exact test.

No significant difference in complication rates between the two groups was observed as shown in Table 2. Four patients had vault hematoma in LAVH of which three were spontaneously resolved and one patient needed surgical evacuation, whereas in TLH, one patient had vault hematoma and was surgically evacuated. In TLH, bladder, bowel and ureteric injury were encountered in three patients. Bladder injury was noted intra operatively and was repaired immediately. Bowel and ureteric injury were noted in post operative period and were repaired. One patient in LAVH group was converted to TLH due to adhesion of bowel to posterior surface of uterus. One patient in TLH group was converted to laparotomy due to dense adhesions. There was significant linear correlation between duration of surgery and blood loss in LAVH group $(\mathrm{P}=0.002)$ but not in TLH $(\mathrm{P}=0.74)$.

\section{DISCUSSION}

Since laparoscopic hysterectomy was first described by Reich and coworkers in 1989, to date, laparoscopic surgery has evolved rapidly worldwide. It has been accepted that laparoscopic hysterectomies reduce the rate of laparotomies when vaginal hysterectomy is observed to be challenging in patients with a history of an adnexal mass, endometriosis, pelvic pain, and prior abdominal surgery, or in patients with a narrow pubic arch or poor vaginal descent.

Since the Gynaecologists are trained with vaginal hysterectomy ( $\mathrm{VH})$ right from their training period, it was easy to shift to LAVH from VH. But TLH required technical expertise and needed a long learning curve.
Hence, in our centre initially we introduced LAVH as minimally invasive procedure. From June 2014, we have started doing TLH after training. Here, we have discussed and compared our hospital outcomes with other reported studies. A meta-analysis included more than 300 patients in each procedure done by Guo et al, comparing LAVH and $\mathrm{VH}$, showed no difference in blood loss, hospital stay or complications, but LAVH required a longer operating time and the authors concluded $\mathrm{VH}$ was the preferred surgery. ${ }^{6}$ In a metaanalysis comparing $\mathrm{VH}$ and $\mathrm{TLH}$, TLH was associated with shorter hospital stay, with no differences in complications, blood loss or urinary tract injury. ${ }^{7}$ These authors concluded that TLH might be superior to $\mathrm{VH}$.

There have been fewer reports comparing LAVH and TLH in a single facility. In a comparative study between LAVH and TLH, Roy et al. suggested that TLH required a significantly longer operative time, but it resulted in less blood loss. ${ }^{8}$ There were no significant differences in postoperative outcomes. Jin woo shin et al. compared 72 LAVH cases and 96 TLH cases and concluded that LAVH was superior for relatively large uteri, eventhough both the procedures are reported to be safe. ${ }^{9}$

Long et al. compared 60 cases of LAVH and 41 cases of TLH and found that TLH resulted in relatively less blood loss, longer operating time and there is no significant difference in hospital stay. ${ }^{10}$ In a comparative study of TLH, LAVH, TAH and VH in 2014, a prospective study by Lkhagvadulam et al, compared LAVH, VH, and TLH in 110 women and they concluded that LAVH is associated with less hospital stay, low complication rates, lack of severe post-operative complications but it took longer operating time. ${ }^{11}$

V Da Costa et al, conducted a retrospective study by comparing 10 women in TLH and 22 women in $\mathrm{VH}$ and concluded TLH was associated with longer operating time. $^{12}$

In present study, author reported experience gained in introducing TLH. Blood loss was more with TLH than LAVH and the result depend on our experience. Operating time is less in LAVH than TLH in our study which is attributed to our experience and we selected parous patients for LAVH. A significant number of patients with cesarean delivery were selected for TLH. Hospital stay was less in LAVH than TLH but the complications rate was not significant between two groups. Prolonged duration of surgery was associated with increased blood loss in LAVH but not in TLH. The proportion of hysterectomies performed with laparoscopic assistance has increased in this unit. Although gynecologists should be trained in all three routes previously described (vaginal, laparoscopic and abdominal), a rational algorithm should be employed in clinical decisions. In modern gynecological practice one should be able to do more LAVH and TLH instead of $\mathrm{TAH}$, as there are fewer complications in the expert's 
hands, shorter hospital stay, overall cost effectiveness, but the decision depends heavily on the skills of the surgeon and the facilities available. VH always enjoys its place because it is simple, cost effective, no scar, almost pain free and can be performed even in a smaller centre. Laparoscopy should be used primarily and effectively to convert a TAH to a $\mathrm{VH}$ and thereby reducing the complications. The clinical situation, co-morbities, facilities available and the experience and skill of the surgeon should decide the type of surgery.

\section{CONCLUSION}

There are many good indications of TLH in patients with previous abdominal surgery, multiple fibroids, limited vaginal access, nulliparity or broad ligament myoma. In other indications LAVH should be considered a better option because of less operative time and reduced cost of surgery. Total Laparoscopic hysterectomy has a genuine concern of ureteric injury. So, in normal uncomplicated uterus LAVH or even vaginal hysterectomy has advantages and remains an excellent option.

Funding: No funding sources

Conflict of interest: None declared

Ethical approval: The study was approved by the Institutional Ethics Committee

\section{REFERENCES}

1. Liu CY. Laparoscopic hysterectomy: A review of 72 cases. J Reprod Med. 1992;37:351-4.

2. Kung FT, Hwang HR, Lin H, Tai MC, Hsieh CH, Chang SY. Comparison of laparoscopically assisted vaginal hysterectomy and abdominal hysterectomy in Taiwan. J Formos Med Assoc. 1996;95:769-75.

3. Phipps JH, John M, Nayak S. Comparison of laparoscopically assisted vaginal hysterectomy and bilateral salpingo-oophorectomy with conventional abdominal hysterectomy and bilateral salpingooophorectomy. Br J Obstet Gynaecol. 1993;100:698700 .

4. Johns DA, Carrerra B, Jones J, Deleon F, Vincent R, Safely C. The medical and economic impact of laparoscopically assisted vaginal hysterectomy in a large, metropolitan, not-forprofit hospital. Am J Obstet Gynecol. 1995;172:1709-19.

5. Harris MB, Olive DI. Changing hysterectomy patterns after introduction of laparoscopically assisted vaginal hysterectomy. Am J Obstet Gynecol. 1994;171:340-4.

6. Guo Y, Tian X, Wang L. Laparoscopically assisted vaginal hysterectomy vs vaginal hysterectomy: meta analysis. J Minim Invasive Gynecol. 2013;20(1):1521.

7. Gendy R, Walsh CA, Walsh SR, Karantanis E. Vaginal hysterectomy versus total laparoscopic hysterectomy for benign disease: a metaanalysis of randomized controlled trials. Am J Obstet Gynecol. 2011;204:388-90.

8. Roy KK, Goyal M, Singla S, Sharma JB, Malhotra N, Kumar S. A prospective randomised study of total laparoscopic hysterectomy, laparoscopically assisted vaginal hysterectomy and non-descent vaginal hysterectomy for the treatment of benign diseases of the uterus. Arch Gynecol Obstet. 2011;284:907-12.

9. Shin JW, Lee HH, Lee SP, Park CY. Total Laparoscopic Hysterectomy and LaparoscopyAssisted Vaginal Hysterectomy. JSLS. 2011;15(2):218-21.

10. Long CY, Fang JH, Chen WC, Su JH, Hsu SC. Comparison of total laparoscopic hysterectomy and laparoscopically assisted vaginal hysterectomy. Gynecol Obstet Invest. 2002;53:214-9.

11. Lkhagvadulam D, Amarsanaa. Comparison of total laparoscpic hysterectomy, laparoscopic assisted vaginal hysterectomy, total abdominal hysterectomy and vaginal hysterectomy. Mong Med Sci J. 2014;167(1):23-6.

12. DaCosta V, McIntosh A, Wynter S, Harriott J, Christie L, Frederick-Johnston $\mathrm{S}$ et al. Total laparoscopic hysterectomy versus vaginal hysterectomy at the university hospital of the West Indies: a 5-year retrospective study. West Indian med. 2012;61(9):865-9.

Cite this article as: Mani K, Govindarajan M, Selvaraj V. Comparison of total laparoscopic hysterectomy and laparoscopic assisted vaginal hysterectomy - a 2-year retrospective study. Int J Reprod Contracept Obstet Gynecol 2017;6:966-9. 